\title{
Measurement and Analysis of Broadband UVB Solar Radiation in Spain
}

\author{
José A. Martínez-Lozano*1, María P. Utrillas ${ }^{1}$, José A. Núnez ${ }^{2}$, Anna R. Esteve ${ }^{1}$, José L. Gómez-Amo ${ }^{1,3}$, \\ Victor Estellés ${ }^{1,4}$ and Roberto Pedrós ${ }^{1}$ \\ ${ }^{1}$ Solar Radiation Group, Department of Earth Physics and Thermodynamics, University of Valencia, \\ Burjassot, Valencia, Spain \\ ${ }^{2}$ Centro Meteorológico Territorial de Valencia, Agencia Estatal de Meteorología, Valencia, Spain \\ ${ }^{3}$ Laboratory for Earth Observations and Analyses (UTMEA-TER), ENEA, S. Maria di Galeria, Rome, Italy \\ ${ }^{4}$ Department of Fundamental and Experimental Physics, Electronics and Systems, University of La Laguna, \\ La Laguna, Tenerife, Spain
}

Received 2 February 2012, accepted 31 May 2012, DOI: 10.1111/j.1751-1097.2012.01186.x

\begin{abstract}
Measurements of broadband UVB irradiance (290-315 nm) at 14 locations in Spain for the period 2000-2009 have been used to generate instantaneous, hourly and daily values of irradiance $\left(\mathrm{W} \mathrm{m} \mathrm{m}^{-2}\right)$ and radiant exposure $\left(\mathrm{kJ} \mathrm{m}^{-2}\right)$. These measurements, and its statistical indices, have been analyzed. For the UVB irradiance, the values corresponding to July (maximum) and December (minimum) have been analyzed as representative of the year during the whole period for all locations. For the UVB radiant exposure, the temporal evolution of daily values has been evaluated for all locations to estimate an average yearly behavior. The accumulated radiant exposure for an average year has also been studied for each location. Finally, to determine possible trends in the evolution of the UVB levels, the linear regressions for the mean daily values for all locations have been determined.
\end{abstract}

\section{INTRODUCTION}

UVB radiation causes many biological and chemical processes, which are generally damaging to living organisms in different ways (1-5). The effects of UVB radiation on human beings are mainly observed in the skin, eyes and immune system (5-9). The most common effect of overexposure to UVB radiation is severe sunburn, which leads to higher body temperature, erythema and others ailments $c a 16 \mathrm{~h}$ after the exposure (1012). Moreover, chronic skin overexposure to UVB radiation provokes photoaging (13-15) and other premalignant conditions (16-24).

Although the effects of UVB radiation on human beings have been widely studied, there are also many studies of its effects on animals and vegetation. For example, the impact of UVB radiation has been studied on small animals, such as plankton (25), invertebrates and marine fish (26) and amphibians $(27,28)$, among others. The impact of UVB radiation on vegetation changes with species and crops. As many species grow in a wide latitude range, the natural

*Corresponding author email: jmartine@uv.es (José A. Martínez-Lozano) (c) 2012 Wiley Periodicals, Inc.

Photochemistry and Photobiology (c) 2012 The American Society of Photobiology 0031-8655/12 variation in the plants' genetics, which are found in environments with high UVB radiation, is a natural resource to increase their resistance to UV radiation (29). In particular, the effects of an increase of UVB radiation have been studied on very small plants, such as cyanobacteria, phytoplankton, microalgae and other aquatic organisms (30), and algae (31). The effects of UVB radiation on bigger plants, herbaceous or woody, have also been studied (32-36).

Fewer studies have been dedicated to the changes caused by UVB radiation, on natural ecosystems, as the effects of UVB radiation on an ecosystem level are worse known than on a molecular or organism level. Many important consequences can be indirect effects of the high UVB radiation through changes in the chemical composition and shape of the plants, or through changes in the abiotic environment. These indirect effects can include changes in the sensitivity of plants to be attacked by insects and pathogen elements both in natural and agricultural ecosystems. The indirect effects of UVB radiation on plants causing changes in their shape or function usually appear through genetic alteration rather than as damage to them. The production of some crops can decrease due to high UVB radiation, but other varieties are not affected. This effect can be difficult to evaluate for forests if the UVB effects are accumulated over several years. The effects of an elevated UVB radiation must be considered together with other climatic changes such as the increase of temperature or $\mathrm{CO}_{2}$ levels, which can modify the response to UVB radiation, especially in vegetation (37-39), but also in animal microorganisms (40).

Despite the great impact of UVB radiation on ecosystems and living organisms, few measurements of UVB radiation are registered all over the world. Usually, the measured parameter is the ultraviolet erythemal radiation (UVER), which represents the response of human skin to erythema or sunburn. These measurements are made with radiometers, spectroradiometers and Brewer spectrophotometers (41-45), and only a few studies have analyzed strictly UVB measurements (46-50).

The objective of this study was to analyze the UVB measurements made in 14 locations of the Iberian Peninsula during 10 continuous years by the Spanish UVB Radiometric Network (41), managed by the State Agency of Meteorology of Spain (AEMET). 


\section{MATERIALS AND METHODS}

The Spanish UVB Radiometric Network (41) was installed in 1998 by the State Agency of Meteorology (AEMET; formerly known as the National Institute of Meteorology [INM]), and nowadays it is composed by 26 stations which measure UVB radiation and 7 stations that also measure ozone. In this study, to work with homogeneous data series, we have only considered measurement stations with little difference in latitude (the stations in the Canary Islands have not been considered) and coincident data during a period of 10 years (2000-2009). The geographical coordinates and elevations above sea level for the 14 measurement stations considered are detailed in Table 1. Although the measurements were registered over 10 years (2000-2009) for all the stations, several of them have small periods without data (Table 1). The geographical distribution of the considered measurement stations is not homogeneous, with a great number of stations in the Mediterranean coast and wide areas without covering.

Table 1. Coordinates of the stations of the Spanish UVB Radiometric Network and available data during the period 2000-2009.

\begin{tabular}{|c|c|c|c|c|}
\hline Stations & Latitude & Longitude & Altitude (m) & $\begin{array}{l}\text { Period without } \\
\text { data }\end{array}$ \\
\hline A Coruña & $43^{\circ} 21^{\prime} \mathrm{N}$ & $8^{\circ} 25^{\prime} \mathrm{W}$ & 67 & \\
\hline Santander & $43^{\circ} 28^{\prime} \mathrm{N}$ & $3^{\circ} 49^{\prime} \mathrm{W}$ & 79 & \\
\hline Valladolid & $41^{\circ} 39^{\prime} \mathrm{N}$ & $4^{\circ} 46^{\prime} \mathrm{W}$ & 740 & Year 2003 \\
\hline Zaragoza & $41^{\circ} 38^{\prime} \mathrm{N}$ & $0^{\circ} 55^{\prime} \mathrm{W}$ & 250 & $\begin{array}{l}\text { Years } 2008 \\
\text { and } 2009\end{array}$ \\
\hline Barcelona & $41^{\circ} 38^{\prime} \mathrm{N}$ & $2^{\circ} 12^{\prime} \mathrm{E}$ & 60 & $\begin{array}{l}\text { Year } 2000 \text { and } \\
\text { half year } 2006\end{array}$ \\
\hline Madrid & $40^{\circ} 27^{\prime} \mathrm{N}$ & $3^{\circ} 44^{\prime} \mathrm{W}$ & 680 & \\
\hline Roquetas & $40^{\circ} 49^{\prime} \mathrm{N}$ & $0^{\circ} 30^{\prime} \mathrm{E}$ & 44 & $\begin{array}{l}\text { Half years } 2000 \\
\text { and } 2001 \text {, and } \\
\text { years } 2002 \\
\text { and } 2005\end{array}$ \\
\hline $\begin{array}{l}\text { Palma de } \\
\text { Mallorca }\end{array}$ & $39^{\circ} 33^{\prime} \mathrm{N}$ & $2^{\circ} 37^{\prime} \mathrm{E}$ & 10 & $\begin{array}{l}\text { Years } 2008 \\
\text { and } 2009\end{array}$ \\
\hline Valencia & $39^{\circ} 29^{\prime} \mathrm{N}$ & $0^{\circ} 23^{\prime} \mathrm{W}$ & 23 & \\
\hline Ciudad Real & $38^{\circ} 59^{\prime} \mathrm{N}$ & $3^{\circ} 55^{\prime} \mathrm{W}$ & 628 & \\
\hline Badajoz & $38^{\circ} 53^{\prime} \mathrm{N}$ & $6^{\circ} 58^{\prime} \mathrm{W}$ & 186 & $\begin{array}{r}\text { Half year } 2000, \\
\text { and year } 2001\end{array}$ \\
\hline Murcia & $38^{\circ} 00^{\prime} \mathrm{N}$ & $1^{\circ} 10^{\prime} \mathrm{W}$ & 69 & \\
\hline El Arenosillo & $37^{\circ} 10^{\prime} \mathrm{N}$ & $6^{\circ} 73^{\prime} \mathrm{W}$ & 41 & $\begin{array}{l}\text { Years } 2000,2001, \\
2002,2003 \text {, and } \\
\text { half year } 2006\end{array}$ \\
\hline Málaga & $36^{\circ} 43^{\prime} \mathrm{N}$ & $4^{\circ} 29^{\prime} \mathrm{W}$ & 61 & $\begin{array}{r}\text { Half year } 2000 \text {, } \\
\text { and year } 2002\end{array}$ \\
\hline
\end{tabular}

The UVB radiation is measured using UVB-1 radiometers by YES (Yankee Environmental Systems), which have a spectral range of 280 $400 \mathrm{~nm}$, and these measurements are daily transmitted, processed and stored in the National Radiometric Centre in Madrid. For the determination of total UVB irradiance the manufacturer provides a detailed tabulation of the weighting factors as a function of the solar zenith angle for the UVB-1 instrument (51).

The calibration of the YES UVB-1 radiometers is periodically performed at the National Radiometric Centre in Madrid, and it consists of the measurement of the angular and spectral response of the radiometer indoor, and a comparison with a reference YES UVB-1 radiometer and a Brewer spectroradiometer outdoor. The calibration result is a global constant and a calibration matrix, which is a function of the solar zenith angle and the total column ozone.

\section{RESULTS AND DISCUSSION}

\section{Analysis of UVB irradiance values}

The study of the most representative statistical indices of UVB irradiance has been carried out for all the measurement stations. Monthly statistics for the whole measurement period (2000-2009) were calculated using daily values. The most representative statistical indices are analyzed. The skewness (a measure of the asymmetry of the probability distribution of a real-valued random variable) and the kurtosis (a descriptor of the shape of the probability distribution) of the distribution have also been studied.

For all the 14 measurement stations, the monthly statistics have been analyzed. As an example, Tables 2 and 3 show the results obtained during July and December at solar noon. Those months usually present the highest and lowest records of UVB irradiance for all the stations (Table 4). Only in Barcelona the UVB irradiance is slightly higher in June than in July. The values of the arithmetic mean and the median (described as the numerical value separating the higher half of the probability distribution from the lower half) are very similar, with the difference between them following no pattern for any month. On July, these differences represent always $<3 \%$ of the mean value (e.g. Madrid, Ciudad Real, Valencia and Murcia). In some stations, these relative differences reach values between $3 \%$ and $5 \%$ at the beginning and the end of the day, (e.g. A Coruña, Santander, Valladolid, Zaragoza, Badajoz, Palma de Mallorca, El Arenosillo and Málaga). There are some stations where these relative differences reach $3 \%$ and $4 \%$ only in specific cases at solar noon (Barcelona [twice],

Table 2. Statistical indices of the hourly UVB irradiance, in July, at solar noon for each location.

\begin{tabular}{|c|c|c|c|c|c|c|c|c|c|c|c|c|c|}
\hline & Mean & $\mathrm{SD}$ & Median & $\mathrm{Mx}$ & $\mathrm{Mn}$ & $Q_{1}$ & $Q_{3}$ & $Q_{3}-Q_{1}$ & $V$ & P5 & P95 & Kurtosis & Skewness \\
\hline A Coruña & 1255 & 128 & 1242 & 1544 & 1026 & 1169 & 1349 & 179 & 7.1 & 1099 & 1482 & -0.4 & -0.4 \\
\hline Santander & 1224 & 124 & 1217 & 1514 & 952 & 1126 & 1318 & 191 & 7.8 & 1054 & 1401 & -0.2 & -0.1 \\
\hline Valladolid & 1623 & 94 & 1646 & 1788 & 1375 & 1558 & 1692 & 133 & 4.1 & 1463 & 1737 & 0.3 & -0.7 \\
\hline Zaragoza & 1498 & 75 & 1525 & 1601 & 1341 & 1447 & 1563 & 115 & 3.8 & 1363 & 1591 & -0.7 & -0.6 \\
\hline Barcelona & 1317 & 110 & 1362 & 1460 & 1039 & 1274 & 1388 & 113 & 4.3 & 1089 & 1430 & 0.8 & -1.2 \\
\hline Madrid & 1665 & 64 & 1683 & 1769 & 1482 & 1625 & 1708 & 83 & 2.5 & 1567 & 1748 & 0.7 & -0.8 \\
\hline Roquetes & 1419 & 155 & 1466 & 1617 & 1007 & 1331 & 1521 & 189 & 6.6 & 1140 & 1612 & 0.5 & -1.0 \\
\hline Palma & 1451 & 102 & 1460 & 1608 & 1208 & 1382 & 1519 & 136 & 4.7 & 1287 & 1604 & -0.4 & -0.3 \\
\hline Valencia & 1389 & 80 & 1410 & 1515 & 1206 & 1339 & 1449 & 110 & 4.0 & 1258 & 1507 & -0.6 & -0.4 \\
\hline Ciudad real & 1726 & 87 & 1753 & 1855 & 1486 & 1671 & 1793 & 121 & 3.5 & 1574 & 1824 & 1.0 & -1.0 \\
\hline Badajoz & 1680 & 69 & 1697 & 1793 & 1479 & 1657 & 1727 & 69 & 2.1 & 1549 & 1751 & 1.7 & -1.2 \\
\hline Murcia & 1584 & 75 & 1589 & 1687 & 1350 & 1561 & 1629 & 68 & 2.1 & 1459 & 1685 & 2.5 & -1.2 \\
\hline Arenosillo & 1644 & 113 & 1675 & 1825 & 1346 & 1593 & 1727 & 133 & 4.0 & 1410 & 1781 & 1.3 & -1.1 \\
\hline Malaga & 1564 & 77 & 1585 & 1679 & 1358 & 1524 & 1604 & 79 & 2.6 & 1404 & 1665 & 1.5 & -1.1 \\
\hline
\end{tabular}


Table 3. Statistical indices of the hourly UVB irradiance, in December, at solar noon for each location.

\begin{tabular}{lccccccccccccc}
\hline & Mean & SD & Median & Mx & Mn & $Q_{1}$ & $Q_{3}$ & $Q_{3}-Q_{1}$ & $V$ & P5 & P95 & Kurtosis & Skewness \\
\hline A Coruña & 160 & 23 & 166 & 374 & 112 & 211 & 315 & 103 & 19.7 & 167 & 359 & -0.8 & 0.1 \\
Santander & 168 & 21 & 169 & 400 & 138 & 194 & 283 & 88 & 18.6 & 154 & 329 & -0.1 & 0.5 \\
Valladolid & 209 & 23 & 208 & 514 & 161 & 257 & 394 & 136 & 20.9 & 182 & 466 & -0.9 & 0.1 \\
Zaragoza & 217 & 29 & 217 & 543 & 198 & 285 & 410 & 124 & 17.8 & 222 & 492 & -0.2 & 0.4 \\
Barcelona & 218 & 23 & 213 & 527 & 242 & 289 & 399 & 109 & 15.9 & 254 & 496 & 0.0 & 0.9 \\
Madrid & 238 & 20 & 236 & 517 & 213 & 315 & 459 & 144 & 18.7 & 235 & 508 & -1.0 & 0.1 \\
Roquetes & 218 & 47 & 220 & 525 & 253 & 337 & 436 & 98 & 12.7 & 288 & 506 & -0.6 & 0.0 \\
Palma & 268 & 33 & 272 & 491 & 262 & 336 & 402 & 65 & 8.8 & 301 & 476 & -0.2 & 0.4 \\
Valencia & 238 & 31 & 245 & 538 & 254 & 329 & 418 & 88 & 11.8 & 268 & 488 & -0.2 & 0.3 \\
Ciudad ral & 286 & 23 & 280 & 649 & 260 & 371 & 519 & 148 & 16.7 & 293 & 588 & -0.5 & 0.2 \\
Badajoz & 275 & 36 & 276 & 595 & 271 & 371 & 492 & 121 & 14.0 & 298 & 571 & -0.7 & 0.2 \\
Murcia & 307 & 31 & 312 & 636 & 335 & 401 & 503 & 101 & 11.2 & 338 & 582 & -0.2 & 0.5 \\
Arenosillo & 348 & 53 & 359 & 695 & 300 & 432 & 590 & 157 & 15.4 & 321 & 680 & -0.8 & 0.1 \\
Malaga & 343 & 34 & 340 & 655 & 364 & 425 & 542 & 117 & 12.1 & 373 & 605 & -0.9 & 0.2 \\
& & & & & & & & & & & & \\
\hline
\end{tabular}

Roquetes and Badajoz [once]). On December, these differences are in all cases $<3 \%$ at A Coruña, Santander, Palma de Mallorca, Ciudad Real, Badajoz and Murcia. Relative differences between $3 \%$ and $5 \%$ are observed close to sunrise and sunset in Barcelona, Madrid, Roquetes, Valencia and El Arenosillo. Differences greater than 3\% and up to $7 \%$ were observed occasionally at noon at Zaragoza (once), Valladolid, Barcelona, Roquetes and Valencia (twice) and El Arenosillo (three times).

In July, the absolute maxima oscillate between $1460 \mathrm{~mW} \mathrm{~m}^{-2}$ in Barcelona and $1855 \mathrm{~mW} \mathrm{~m}^{-2}$ in Ciudad Real, whereas the absolute minima vary from $953 \mathrm{~mW} \mathrm{~m}^{-2}$ in Santander to $1486 \mathrm{~mW} \mathrm{~m}^{-2}$ in Ciudad Real. The difference (in percentage) between the values of the absolute minimum and the $\mathrm{P}_{5}$ percentile vary between $1.9 \%$ (Valencia) and $12.5 \%$ (Murcia). These are systematically larger than those observed between the absolute maxima and $\mathrm{P}_{95}$ percentiles, which vary between $0.3 \%$ (Badajoz) and $7.0 \%$ (Santander). The absolute extreme values (maximum and minimum) have been compared against their corresponding quartile values $\left(Q_{3}\right.$ and $Q_{1}$, respectively) to understand if they are representative of the UVB records for all the stations. The differences between the $Q_{1}$ quartiles and the absolute minima vary from 7\% (Madrid) to $21 \%$ (Roquetes), with a mean value of $12 \%$. The mean value of the difference between the $Q_{3}$ quartiles and the absolute maxima is 5\%, and oscillates between 2\% (Valladolid) and $12 \%$ (Santander). Therefore, these maximum and minimum values can be considered representative of the UVB irradiance at solar noon as they are not uncommon extreme values for July.

In December, the absolute maxima of the UVB irradiance observed at noon vary from $374 \mathrm{~mW} \mathrm{~m}^{-2}$ in A Coruña to $696 \mathrm{~mW} \mathrm{~m}^{-2}$ in El Arenosillo, whereas the absolute minima are between $112 \mathrm{~mW} \mathrm{~m}^{-2}$ in A Coruña and $365 \mathrm{~mW} \mathrm{~m}^{-2}$ in Malaga. As it happened for July, the difference between the values of the absolute minimum and the $\mathrm{P}_{5}$ percentile is systematically larger than that observed between the absolute maxima and $\mathrm{P}_{95}$ percentiles. These differences vary from $1.5 \%$ (Madrid) to $17 \%$ (Santander), with a mean value of $6.6 \%$ (for the absolute minima and $\mathrm{P}_{5}$ ), and from $1 \%$ (Murcia) to $49 \%$ (A Coruña), with a mean value of $11.7 \%$ (for the absolute maxima and $\mathrm{P}_{95}$ ). The comparison of the extreme values with their corresponding quartiles shows a mean value of $39 \%$ for the difference between the $Q_{1}$ quartiles and the absolute minima, and a variation between $10 \%$ (Barcelona) and $88 \%$ (A Coruña). The differences between the $Q_{3}$ quartiles and the absolute maxima oscillate from $11 \%$ (Madrid) to $29 \%$ (Santander), and show a mean value of $19 \%$. These values are greater than those observed in July, indicating that the extreme values of the UBV irradiance at solar noon are less representative in December than in July.

The coefficient of interquartilar variation ( $V$ index, defined as $\left.V=100\left(Q_{3}-Q_{1}\right) /\left(Q_{3}+Q_{1}\right)\right)$, which is a nonparametric measurement that does not depend on the shape of the population distribution, has been used to study the variability of the UVB irradiance at solar noon. It can be observed that July presents low values of the $V$ index, meaning high stability, that fluctuate between 2.1 in Badajoz and Murcia and 7.8 in Santader, with a mean value of 4.2. Less stability is observed in December, with the $V$ index varying from 8.8 in Palma de Mallorca to 20.9 in Valladolid, with a mean value of 15.3. This higher value of the $V$ index in December is due to the major presence of clouds during winter, leading to less stability in the UVB levels.

The skewness in July is low, and always displays negative values, indicating that the UVB irradiance values at noon are slightly shifted to the left of the arithmetic mean. It exceeds the unity only in Roquetes and Ciudad Real (-1.0), El Arenosillo and Málaga (-1.1) and Barcelona, Badajoz and Murcia (-1.2). In December, the skewness is lower than that obtained in July, and always displays positive values, which indicates that the UVB irradiance values at solar noon are slightly shifted to the right of the arithmetic mean. It only displays a value greater than 0.5 in Barcelona (with a value of 0.9).

The kurtosis in July displays values generally $<1$ for all the stations. It only takes values $>1$ in the southern part of the Iberian Peninsula: Ciudad Real (1.0), Badajoz (1.7), Murcia (1.5), El Arenosillo (1.3) and Málaga (1.5). In those cases, the distribution function of the UVB irradiance is leptokurtic, with most data close to the mean value and a larger peak than the normal distribution. In December, the kurtosis reaches unity only in Madrid (-1.0). In this month, the UVB irradiance distribution function is always platykurtic, with the data showing a weaker peak than the normal distribution function.

For each station, we have calculated the monthly averages of the hourly mean values of the UVB irradiance. The daily 

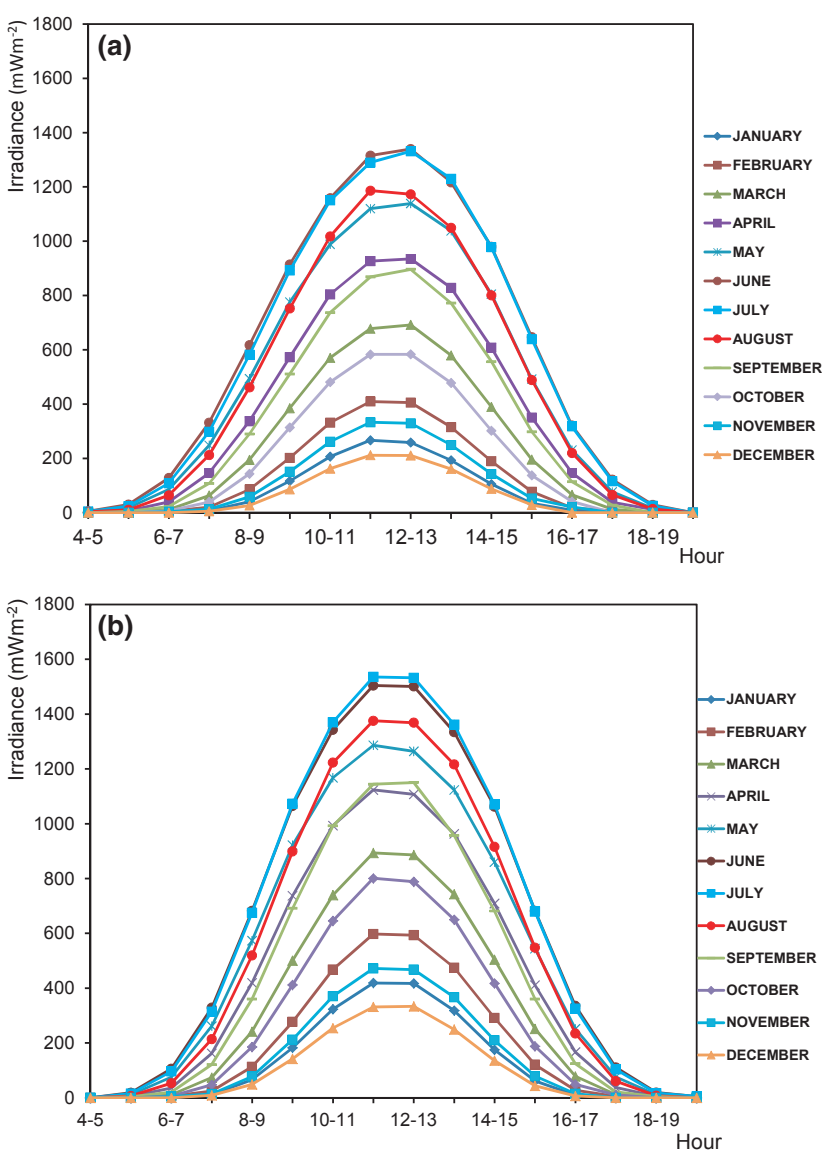

Figure 1. Daily evolution of the monthly mean hourly values of UVB irradiance $\left(\mathrm{mW} \mathrm{m}^{-2}\right)$ in: (a) Barcelona and (b) Malaga.

evolution of these values for the period 2000-2009 for all the stations shows great symmetry respect to the maximum value is observed. In all cases, the peak irradiance is placed at solar noon in July, except in Barcelona, where it is observed in June. The minimum values are obtained in all cases in December. As an example, Fig. 1 shows the daily evolution of monthly mean hourly values of UVB irradiance $\left(\mathrm{mW} \mathrm{m}^{-2}\right)$ during the period 2000-2009, in Barcelona and Málaga.

\section{Analysis of UVB radiant exposure values}

The most representative statistical indices of daily integrated values of the UVB radiant exposure in $\mathrm{kJ} \mathrm{m}^{-2}$ have also been analyzed for all the 14 stations, similarly to the hourly irradiance analysis. The median and the arithmetic mean values are very much alike. The differences between them do not seem to follow any pattern, except that the average is always greater than the median. The relative differences range from $2 \%$ in Málaga to $10 \%$ in El Arenosillo (Huelva), with an average of $6 \%$.

The absolute maximum values oscillate between $33966 \mathrm{~J} \mathrm{~m}^{-2}$ in Santander and $44122 \mathrm{~J} \mathrm{~m}^{-2}$ in Valencia, both in July. The Zaragoza, Madrid, Palma de Mallorca and El Arenosillo (Huelva) stations have values above $40000 \mathrm{~J} \mathrm{~m}^{-2}$ in June and July, as well as Valencia in June, July and August. On the other hand, the absolute minimum values oscillate between $1795 \mathrm{~J} \mathrm{~m}^{-2}$ in A Coruña and $6362 \mathrm{~J} \mathrm{~m}^{-2}$ in Málaga, 
both in December. The differences between the absolute minima and the $\mathrm{P}_{5}$ percentiles (in percentage) are significantly higher than those between the absolute maxima and the $\mathrm{P}_{95}$ percentiles. In the first case, the differences range from $15 \%$ (Valencia) to $54 \%$ (El Arenosillo), whereas in the second case the differences are comprised between 4\% (Badajoz) and 13\% (Santander).

To check whether the absolute extreme values (maximum and minimum) are representative of the stations we have compared them with their respective quartiles $\left(Q_{3}\right.$ and $Q_{1}$, respectively). The differences between the $Q_{1}$ quartiles and the minima range from $80 \%$ (Malaga) to $192 \%$ (A Coruña and Zaragoza), with an average of $138 \%$, which means that the minima are atypical values of the UVB radiant exposure for all the stations. The differences between the $Q_{3}$ quartiles and the maxima oscillate between 21\% (Murcia and Málaga) and $30 \%$ (Santander and Barcelona), with an average of $25 \%$, indicating that the maxima cannot be considered representative of the UVB radiant exposure at solar noon for all the stations.

The variability of the UVB radiant exposure has been assessed by means of the $V$ index, which fluctuates between 2.0 (Valladolid and Palma de Mallorca) and 7.0 (Roquetes, Tarragona), with an average of 3.6. The $V$ index reaches its lowest value during summer, implying higher stability of the UVB radiant exposure, which could be due to a lesser presence of clouds during summer for all the stations.

The skewness is very low. The average values range between 0.1 and 0.3 , with monthly peaks between 1.2 and -2.1 . The whole set of values is slightly above the average for all the stations. Although the distribution is random, it exhibits a positive asymmetry. On the other hand, the kurtosis is also random for some stations at particular months. The average for each station is around -1.4 , therefore the distribution is platykurtic. This means that the distribution has a flatter peak around its mean, which causes thin tails within the distribution.

We have calculated the radiant exposure values at each station for an average year. For this, we have used daily averages for the whole 10-year database. The daily values of the UVB radiant exposure for this average year show large shifts, suggesting that the prediction of radiant exposure is not possible on a daily scale. The monthly mean values of the UVB radiant exposure present a quite regular, but asymmetrical variation, with the maximum values occurring in June and July, whereas the minimum values occur in December. The drop in the summer-autumn period (August-November) is considerably steeper than the rise in the winter-spring period (February-June). This unevenness suggests the use of median values instead of arithmetic mean values in the statistical analysis of the data. As an example, Fig. 2 shows the annual evolution of daily mean values and monthly mean daily values of UVB radiant exposure $\left(\mathrm{J} \mathrm{m}^{-2}\right)$ during the period 2000-2009, in Málaga.

In the study of the biological effects of UVB radiation, it can be interesting to know the accumulated UVB solar radiant exposure $\left(\mathrm{J} \mathrm{m}^{-2}\right)$ on a time period. In our case, the accumulated UVB hourly values exceed $40000 \mathrm{~J} \mathrm{~m}^{-2}$ in July for the Madrid, Valencia and Palma de Mallorca stations, whereas in December only the Malaga station is above $5000 \mathrm{~J} \mathrm{~m}^{-2}$. We can conclude that the maximum monthly radiant exposure occurs in July, except for Barcelona station where it happens in

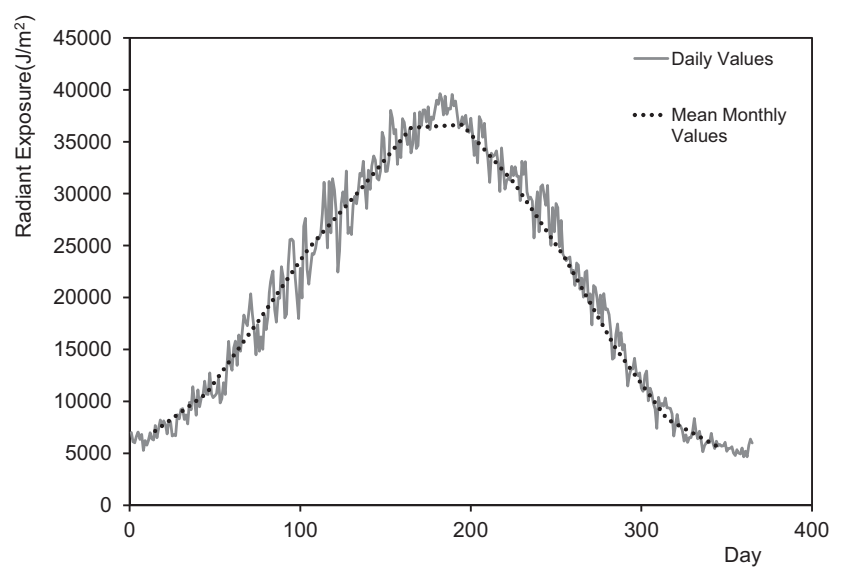

Figure 2. Annual evolution of daily mean values and monthly mean daily values of UVB radiant exposure $\left(\mathrm{J} \mathrm{m}^{-2}\right)$ during the period 2000 2009 in Málaga.
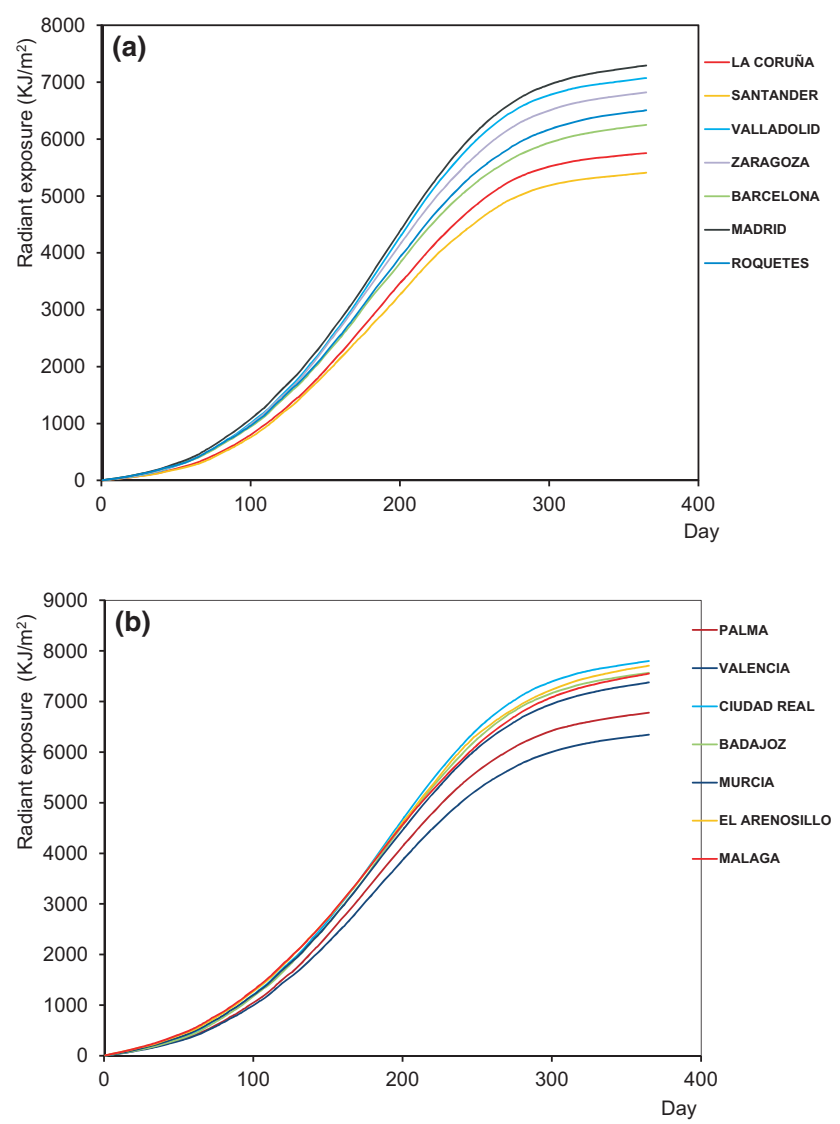

Figure 3. UVB radiant exposure accumulated during an average year $\left(\mathrm{kJ} \mathrm{m}^{-2}\right)$ at: (a) A Coruña, Santander, Valladolid, Zaragoza, Barcelona, Madrid and Roquetes; (b) Badajoz, Ciudad Real, Valencia, Palma de Mallorca, Murcia, El Arenosillo and Málaga.

June. On the other hand, the minimum radiant exposure occurs in December for all stations. We have also studied the mean daily values of the accumulated UVB radiant exposure for an average year. The values oscillate between $5400 \mathrm{~kJ} \mathrm{~m}^{-2}$ in Santander and $7800 \mathrm{~kJ} \mathrm{~m}^{-2}$ in Ciudad Real (Fig. 3). 


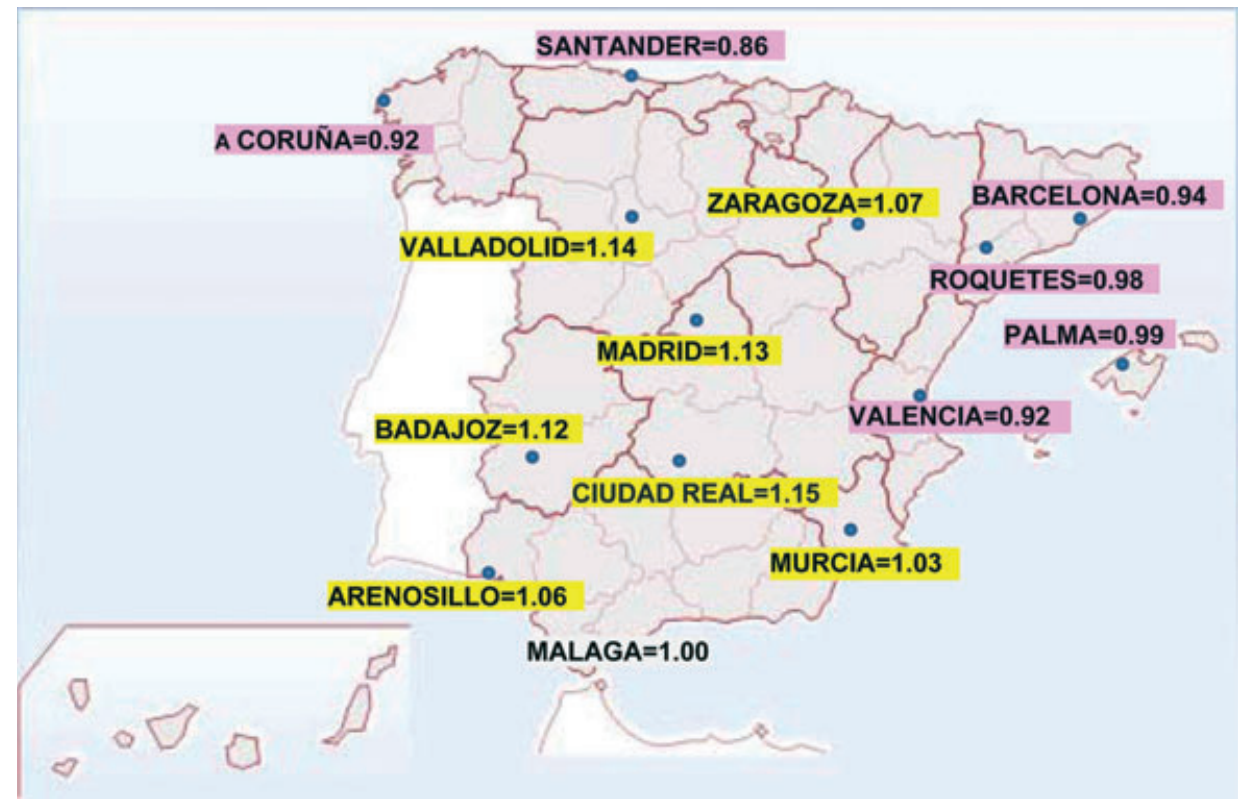

Figure 4. Slopes of the linear regressions between measurement stations of the cumulated values of the UVB radiant exposure during an average day, considering Malaga as the reference station.

To study the differences between the measurement stations we have created a standard year for each of them using cumulated daily values of UVB radiant exposure obtained adding up the hourly mean values calculated from the 10 year data, and then we have calculated the linear regressions for the comparison of each station with Malaga, which is considered as the reference because it is the one with the lowest latitude. Figure 4 shows the slopes of the linear least squares fittings obtained (with $R^{2}>0.93$ for all cases). The slopes for the stations close to the coast present values below 1, which indicates lower values of UVB radiant exposure than those obtained in Malaga, with values between 1\% lower for Palma and $14 \%$ lower for Santander. On the contrary, the slopes for the stations located inland show values above 1, indicating greater values of UVB radiant exposure than those obtained in Malaga, with values between 3\% higher for Murcia and 15\% higher for Ciudad Real. These results agree with the distribution of the mean values obtained previously, and with the continentality effect, which causes that the values inland are lower than in the coast.

\section{Analysis of temporal trends in the UVB values}

We have assessed the temporal trend of the UVB radiant exposure by estimating the linear regressions of the daily mean values during the year for each station. The slopes range from- $(260 \pm 180) \mathrm{J} \mathrm{m}^{-2}$ per year $(-0.9 \%)$ in Roquetes to $(300 \pm 400) \mathrm{J} \mathrm{m}^{-2}$ per year $(0.9 \%)$ in El Arenosillo (Table 5). However, Roquetes and El Arenosillo stations are not representative if we consider the existing data gaps. When we exclude those stations, the slopes also change between $-0.9 \%$ (but now in Zaragoza, Fig. 5a) and $0.9 \%$ (in Badajoz, Fig. 5b). Figure 5 also includes the fitting line of the daily mean irradiance versus the Julian day. The daily analysis and the measurement errors discussed in Section 2 lead us to the conclusion that the radiant exposure in the Iberian Peninsula
Table 5. Linear regressions for the annual evolution of the UVB irradiance for each location.

\begin{tabular}{lcccr}
\hline & $\begin{array}{c}\text { Slope } \\
\left(\mathrm{J} \mathrm{m}^{-2}\right. \\
\text { per year })\end{array}$ & $\begin{array}{c}\text { Slope error } \\
\left(\mathrm{J} \mathrm{m}^{-2}\right. \\
\text { per year })\end{array}$ & $\begin{array}{c}\text { Mean } \\
\text { value } \\
\left(\mathrm{J} \mathrm{m}^{-2}\right)\end{array}$ & Slope $(\%)$ \\
\hline A Coruña & -50 & -6 & 15840 & -0.3 \\
Santander & 30 & 120 & 15367 & 0.2 \\
Valladolid & 180 & 100 & 19462 & 0.9 \\
Zaragoza & -170 & -220 & 19567 & -0.9 \\
Barcelona & 140 & 130 & 16850 & 0.8 \\
Madrid & 140 & 80 & 19975 & 0.7 \\
Roquetes & -260 & -180 & 18933 & -1.3 \\
Palma & 100 & 170 & 18788 & 0.5 \\
Valencia & 30 & 120 & 15367 & 0.2 \\
Ciudad real & 30 & 70 & 21360 & 0.1 \\
Badajoz & 180 & 240 & 21175 & 0.9 \\
Murcia & -110 & -80 & 20490 & -0.5 \\
Arenosillo & 300 & 400 & 22463 & 1.3 \\
Malaga & -13 & -230 & 21535 & -0.1 \\
& & & & \\
\hline
\end{tabular}

shows no significant temporal trend in the 10 years comprised between 2000 and 2009 .

\section{CONCLUSIONS}

UVB irradiance (290-315 $\mathrm{nm}$ ) values are presented for the first time for a variety of locations. These correspond to experimental measurements taken at 14 locations in Spain during the period 2000-2009. They have been used to generate hourly and daily values of irradiance $\left(\mathrm{W} \mathrm{m}^{-2}\right)$ and radiant exposure $\left(\mathrm{kJ} \mathrm{m}^{-2}\right)$, and analyzed to produce their most representative statistical indices.

For the irradiance, data from July (maximum irradiance) and December (minimum irradiance) have been selected as representative for the whole analyzed period. In July, both the minimum and maximum values of the UVB irradiance can be 


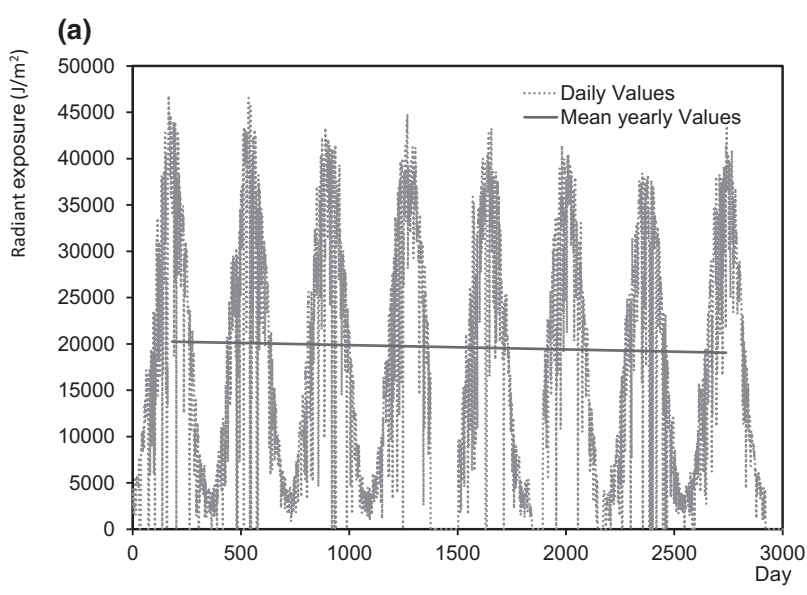

(b)

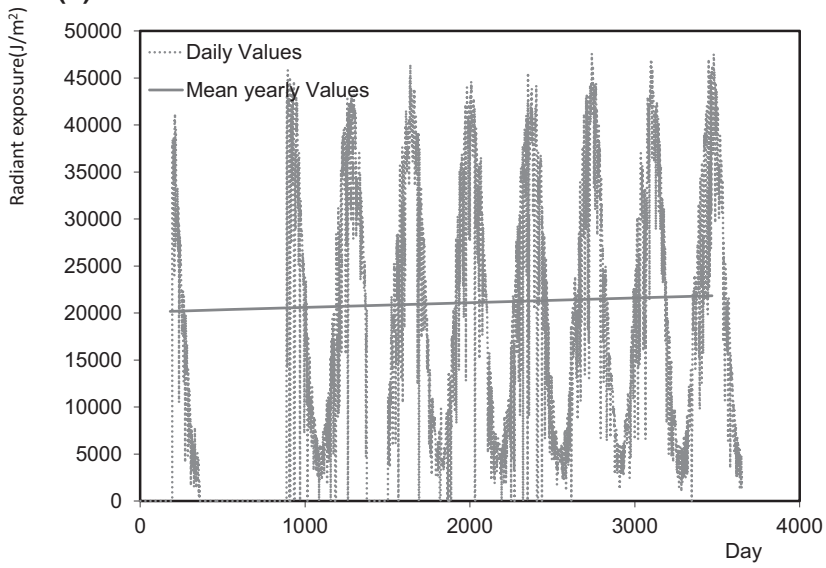

Figure 5. Daily evolution of the daily mean UVB irradiance (in $\mathrm{mW} \mathrm{m}^{-2}$ ) during the period 2000-2009 in (a) Zaragoza; (b) Badajoz. The straight line is the regression of the daily mean UVB irradiance versus the Julian day.

considered representative of the UVB irradiance at solar noon in all the locations. On the contrary, the minimum and maximum values in December cannot be considered representative of the UVB irradiance at solar noon, especially the minima.

The variability of the UVB irradiance at noon is low in July. However, in December the UVB variability is higher, which can be due to the major presence of clouds during winter. The skewness in July is very low and negative in all the locations, and in December it is still lower, although the value is always positive. On turn, the kurtosis in July shows that UVB level distributions are always leptokurtic, in opposition to the platykurtic distributions found in December.

The analysis of monthly and seasonal radiant exposure for all the locations shows equivalent results in comparison with the irradiance. The minima and the maxima are atypical values of UVB radiant exposure for all the locations. The variability of the UVB radiant exposure shows high stability. The skewness is very low. Although the distribution of values is random, the skewness is positive in average. Moreover, the seasonal mean value of the kurtosis is negative, i.e. slightly platykurtic.

The daily values present such a large fluctuation that it seems impossible to predict radiant exposure values for such short-time intervals. The variation of the monthly values is quite regular although asymmetrical, with the maximum values occurring in June and July, whereas the minimum values occur in December. The accumulated radiant exposure for an average year has been seasonally studied. The values vary between $5408 \mathrm{~kJ} \mathrm{~m}^{-2}$ in Santander and $7802 \mathrm{~kJ} \mathrm{~m}^{-2}$ in Ciudad Real.

Finally, to determine possible trends of the evolution of the UVB levels, the mean daily values have been linearly fitted for all the stations. Taking into account the measurement uncertainties, the slopes of the linear regressions do not show significative trends in the evolution of the UVB radiant exposure observed in the Iberian Peninsula during the period 2000-2009.

Acknowledgements - This work was funded by the Ministry of Science and Innovation (MICINN), Spain, through the Projects CGL200907790 and CGL2011-24290, by the Valencia Autonomous Government through the project PROMETEO/2010/064 and by the University of Valencia through the project UV-INV-AE11-41324. V. Estellés and J.L. Gomez-Amo thank the Spanish Ministry of Science and Innovation (MICINN) for the research contract under the Juan de la Cierva program (JCI-2009-04455) and postdoctoral program (EX2010-1192), respectively.

\section{REFERENCES}

1. Frederick, J. E. and D. Lubin (1988) The budget of biologically active radiation in the earth atmosphere system. J. Geophys. Res. 93, 3825-3832.

2. Scotto, J., G. Cotton, F. Urbach, B. Berger and T. R. Fears (1988) Biologically effective ultraviolet radiation: Surface measurements in the United States. 1974 to 1985. Science 239, 762-764.

3. Diffey, B. L. (1991) Solar ultraviolet radiation effects on biological systems. Phys. Med. Biol. 36, 299-328.

4. Longstreth, J. D., F. R. de Gruijl, M. L. Kripke, Y. Takizawa and J. C. van der Leun 1994. Environmental effects of ozone depletion: 1994; assessment, chapter 2. UNEP.

5. Norval, M. (2006) The mechanisms and consequences of ultraviolet-induced immunosuppression. Prog. Biophys. Mol. Biol. 92, 108-118.

6. Diffey, B. L. (1998) Ultraviolet radiation and human health. Clin. Dermatol. 16, 83-89.

7. Godar, D. E. (2005) UV doses worldwide. Photochem. Photobiol. 81, 736-749.

8. Kunz, B. A., D. M. Cahill, P. G. Mohr, M. J. Osmond and E. J. Vonarx (2006) Plant responses to UV radiation and links to pathogen resistance. Int. Rev. Cytol. 255, 1-40.

9. Gallagher, R. P. and T. K. Lee (2006) Adverse effects of ultraviolet radiation: A brief review. Prog. Biophys. Mol. Biol. 92, 119131.

10. Diffey, B. L. (1982) The consistency of studies of ultraviolet erythema in normal human skin. Phys. Med. Biol. 27, 715-720.

11. Berger, D. S. and F. Urbach (1982) A climatology of sun burning ultraviolet radiation. Photochem. Photobiol. 35, 187-192.

12. McKenzie, R., W. A. Matthews and P. V. Johnston (1991) The relationship between erythemal UV and ozone, derived from spectral irradiance measurements. Geophys. Res. Lett. 18, 2269-2272.

13. Goihman-Yahr, M. (1996) Skin aging and photo aging: An outlook. Clin. Dermatol. 14, 153-160.

14. Wlaschek, M., I. Tantcheva-Poór, L. Naderi, W. Ma, L. A. Schneider, Z. Razi-Wolf, J. Schüller and K. Scharffetter-Kochanek (2001) Solar UV irradiation and dermal photo aging. J. Photochem. Photobiol., B 63, 41-51.

15. Rabe, J. H., A. J. Mamelak, P. J. S. McElgunn, W. L. Morison and D. N. Sauder (2006) Photo aging: Mechanisms and repair. J. Am. Acad. Dermatol. 55, 1-19.

16. Scotto, J. and T. R. Fears (1987) The association of solar ultraviolet and skin melanoma incidence among Caucasians in the United States. Cancer Invest. 5, 275-283. 
17. Madronich, S. and F. R. de Gruijl (1993) Skin cancer and UV radiation. Nature 366, 23-28.

18. Kane, R. P. (1998) Ozone depletion, related UVB changes and increased skin cancer incident. Int. J. Climatol. 18, 457-472.

19. Tsao, H. and A. J. Sober (1998) Ultraviolet radiation and malignant melanoma. Clin. Dermatol. 16, 67-73.

20. Alam, M. and D. Ratner (2001) Cutaneous squamous-cell carcinoma. N. Engl. J. Med. 344, 975-983.

21. Armstrong, B. K. and A. Kricker (2001) The epidemiology of UV induced skin cancer. J. Photochem. Photobiol., B 63, 8-18.

22. Rubin, A. I., E. H. Chen and D. Ratner (2005) Basal-cell carcinoma. N. Engl. J. Med. 353, 2262-2269.

23. MacKie, R. N. (2006) Long-term health risk to the skin of ultraviolet radiation. Prog. Biophys. Mol. Biol. 92, 92-96.

24. Ridky, T. W. (2007) Non melanoma skin cancer. J. Am. Acad. Dermatol. 57, 484-501.

25. Davidson, A. T. (1998) The impact of UVB radiation on marine plankton. Mutat. Res. 422, 119-129.

26. Dahms, H. U. and J. S. Lee (2010) UV radiation in marine ectotherms: Molecular effects and responses. Aquat. Toxicol. 97, 3-14.

27. Paul, N. D. and D. Gwynn-Jones (2003) Ecological roles of solar UV radiation: Towards an integrated approach. Trends Ecol. Evol. 18, 48-55.

28. Pahkala, M., A. Laurila and J. Merilä (2003) Effects of ultraviolet$\mathrm{B}$ radiation on behaviour and growth of three species of amphibian larvae. Chemosphere 51, 197-204.

29. Heisler, G. M., R. H. Grant, W. Gao and J. R. Slusser (2004) Solar ultraviolet-B radiation in urban environments: The case of Baltimore, Maryland. Photochem. Photobiol. 80, 422-428.

30. Sinha, R. P. and D.-P. Häder (2002) Life under solar UV radiation in aquatic organisms. Adv. Space Res. 30, 1547-1556.

31. Holzinger, A. and C. Lütz (2006) Algae and UV irradiation: Effects on ultra structure and related metabolic functions. Micron 37, 190-207.

32. Laakso, K. and S. Huttunen (1998) Effects of the ultraviolet-B radiation (UV-B) on conifers: A review. Environ. Pollut. 99, 319-328.

33. Ballaré, C., M. M. Caldwell, S. D. Flint, S. A. Robinson and J. F. Bornman (2011) Effects of solar ultraviolet radiation on terrestrial ecosystems. Patterns, mechanisms, and interactions with climate change. Photochem. Photobiol. Sci. 10, 226-241.

34. Gao, W., Y. Zheng, J. M. Slusser and G. M. Heisler (2003) Impact of enhanced ultraviolet-B irradiance on cotton growth, development, yield, and qualities under field conditions. Agric. For. Meteorol. 120, 241-248.

35. Reddy, K. R., V. G. Kakani, D. Zhao, A. R. Mohammed and W. Gao (2003) Cotton responses to ultraviolet-B radiation: Experimentation and algorithm development. Agric. For. Meteorol. 120, 249-265.

36. Li, F. R., S. L. Peng, B. M. Chen and Y. P. Hou (2010) A metaanalysis of the responses of woody and herbaceous plants to elevated UVB radiation. Acta Oecolog. 36, 1-9.

37. Caldwell, M. M., L. O. Björn, J. F. Bornman, S. D. Flint, G. Kulandaivelu, A. H. Teramura and M. Tevini (1998) Effects of increased solar ultraviolet radiation on terrestrial ecosystems. J. Photochem. Photobiol., B 46, 40-52.

38. Sullivan, J. E. (2005) Possible impacts of changes in UV-B radiation on North American trees and forests. Environ. Pollut. 137, 380-389.

39. Ballaré, C., M. C. Rousseaux, P. S. Searles, J. G. Zaller, C. V. Giordano, T. M. Robson, M. M. Caldwell, O. E. Sala and A. L. Scopel (2001) Impacts of solar ultraviolet-B radiation on terrestrial ecosystems of Tierra del Fuego (southern Argentina): An overview of recent progress. J. Photochem. Photobiol., B 62 , $67-77$.

40. Vermet, M., B. Diaz, H. A. Fuenzalida, C. Camilion, C. R. Booth, C. Casiccia, G. Deferrari, C. Lovengreen, A. Paladini, J. Pedroni, A. Rosales and H. E. Zagarese (2009) Quality of UVER exposure for different biological system along a latitudinal gradient. Photochem. Photobiol. Sci. 8, 1329-1345.

41. Martínez-Lozano, J. A., M. J. Marın, F. Tena, M. P. Utrillas, L. Sanchez-Muniosguren, R. Vergaz, A. de Frutos, J. P. Diaz, F. J. Exposito, B. Morena and J. M. Vilaplana (2002) UV index experimental values during the years 2000 and 2001 from the Spanish broadband UV-B Radiometric Network. Photochem. Photobiol. 76, 181-187.

42. Zaratti, F., R. N. Forno, J. García Fuentes and M. F. Andrade (2003) Erythemally weighted UV variations at two high-altitude locations. J. Geophys. Res. 108, 4263. (DOI: 10.1029/2001 JD000918)

43. Dahlback, A., N. Gelsor, J. J. Stamnes and Y. Gjessing (2007) UV measurements in the $3000-5000 \mathrm{~m}$ altitude region in Tibet. J. Geophys. Res. 112, 1029-1034.

44. Tourpali, K., C. S. Zerefos, D. S. Balis and A. F. Bais (2007) The 11-year solar cycle in stratospheric ozone: Comparison between Umkehr and SBUVv8 and effects on surface erythemal irradiance. J. Geophys. Res. 112, D12306. (DOI: 10.1029/2006JD007760)

45. Herman, J. R. (2010) Global increase in UV irradiance during the past 30 years (1979-2008) estimated from satellite data. J. Geophys. Res. 115, D04203. (DOI: 10.1029/2009JD012219)

46. Palancar, G. G. and B. M. Toselli (2004) Effects of meteorology on the annual and interannual cycle of the UVB and total radiation in Cordoba City, Argentina. Atmos. Environ. 38, 1073-1082.

47. Ogunjobi, K. O. and Y. J. Kim (2004) Ultraviolet $(0.280$ $0.400 \mu \mathrm{m})$ and broadband solar hourly radiation at Kwangju, South Korea: Analysis of their correlation with aerosol optical depth and clearness index. Atmos. Res. 71, 193-214.

48. Cui, X., S. Gu, X. Zhao, J. Wu, T. Kato and Y. Tang (2008) Diurnal and seasonal variations of UV radiation on the northern edge of Qinghi Tibetan Plateau. Agric. For. Meteorol. 148, 144-151.

49. Bilbao, J., P. Salvador and A. De Miguel (2008) UV-B climatology in Central Spain. Int. J. Climatol. 28, 1933-1941.

50. Bilbao, J. and A. de Miguel (2010) Estimation of UV-B irradiation from total global solar meteorological data in central Spain. J. Geophys. Res. 115, D00I09. (DOI: 10.1029/2009JD012505)

51. YES (2008) UVB-1 Ultraviolet Pyranometer. Installation and User Guide. Version 2.04. Yankee Environmental Systems, Inc., Turners Falls, MA. 